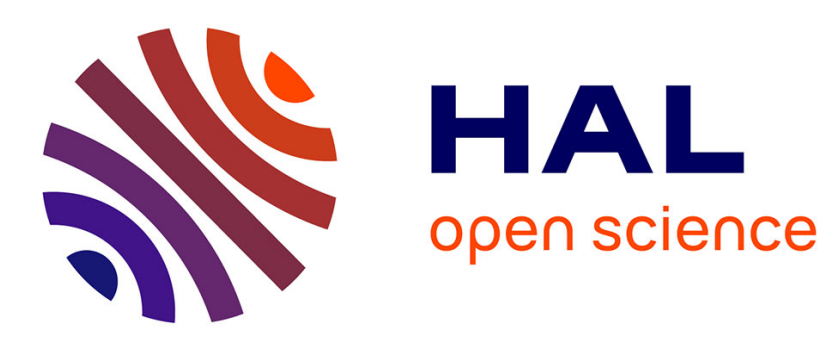

\title{
Measurement of Gravel-Bed Topography: Evaluation Study Applying Statistical Roughness Analysis
}

\author{
Stéphane Bertin, H Friedrich
}

\section{To cite this version:}

Stéphane Bertin, H Friedrich. Measurement of Gravel-Bed Topography: Evaluation Study Applying Statistical Roughness Analysis. Journal of Hydraulic Engineering, 2014, 140, pp.269 - 279. 10.1061/(asce)hy.1943-7900.0000823 . hal-03470757

\section{HAL Id: hal-03470757 https://hal.science/hal-03470757}

Submitted on 21 Dec 2021

HAL is a multi-disciplinary open access archive for the deposit and dissemination of scientific research documents, whether they are published or not. The documents may come from teaching and research institutions in France or abroad, or from public or private research centers.
L'archive ouverte pluridisciplinaire HAL, est destinée au dépôt et à la diffusion de documents scientifiques de niveau recherche, publiés ou non, émanant des établissements d'enseignement et de recherche français ou étrangers, des laboratoires publics ou privés. 


\section{Measurement of gravel-bed topography: an evaluation study applying statistical roughness analysis}

In this two-part study, experiments are conducted to evaluate available topography

7 measurement techniques for gravel-beds in a laboratory flume and to study their suitability for

8 statistical roughness analysis. The available instruments for this study include, (i) an acoustic

9 bed-profiler; (ii) a hand-held laser-scanner; and (iii) two digital consumer cameras forming a stereo-photogrammetric system, and are employed to obtain Digital Elevation Models

11 (DEMs) of water-worked gravel-beds. In the first part of the study, the three measurement

12 techniques are reviewed and their feasibilities for future grain-scale roughness work assessed,

13 based on the obtained elevation datasets. Water-worked gravel-bed topographies are measured with all three available measurement techniques. The analysis of the DEMs concentrates on using Probability Distribution Functions (PDFs) and second-order structure functions of bed elevations. Roughness coefficients are determined and used as a benchmark for comparison of

17 the three measurement techniques. Although, visually, differences in the DEMs obtained with different measurement techniques are observed, the results of the chosen statistical analysis do not disclose the visual differences to the same extent. It is shown that the used stereophotogrammetric system, although theoretically allowing a fast and high-resolution recording

21 process, lacks behind in accuracy. Thus, the second part of the study identifies and presents 22 steps to improve the quality of the obtained stereo-photogrammetric DEMs. A checklist is

'PhD student, Department of Civil and Environmental Engineering, The University of Auckland, Private Bag 92019, Auckland, New Zealand _corresponding author_E-mail: sber081@aucklanduni.ac.nz 
provided, highlighting the improvements made in the follow-up study, in order to obtain a high-quality stereo-photogrammetric DEM. The overview will be useful for other researchers to make use of available low-cost and high-quality consumer camera equipment, to set-up their own, non-proprietary stereo-photogrammetric system.

Subject headings: Topography; Bed roughness; Distance measurement; Photogrammetry.

\section{INTRODUCTION}

\section{Roughness characterization}

With recent research advances and technology improvement, statistical analysis of bed elevations in gravel-bed rivers has become crucial to define roughness parameters, quantify armoring effects, and hence to understand the nature of the river flow.

Traditionally, bed-scale roughness parameters used in bedload transport and flow resistance equations are described using percentiles of the Grain Size Distribution (GSD) of the sediment constituting the bed. The intermediate particle axis is chosen as the base value for GSD, despite it is recognized that the short axis is the one protruding into the flow, and is therefore responsible for the bulk of the resistance to the flow (de Jong 1995; Robert 1990). An equivalent roughness parameter is commonly used, such as Nikuradse's $k_{s}$ set to $3.5 D_{84}$, where $D_{84}$ is the length of the intermediate axis of the sediment particle in the GSD for which 84-\% of the particles are smaller (Clifford et al. 1992). GSD characteristics can be determined with techniques such as sieve analysis, Wolman's (1954) or Fehr's (1987) line-by-number sampling procedures or similar methods, which require disturbance of the gravel-bed surface.

Detailed discussions and comparisons of those methods can be found in the work of Bunte 
and Abt (2001). 2D image-based automated methods became more popular over the last years (Chang and Chung 2012; Detert and Weitbrecht 2012; Graham et al. 2010; Strom et al. 2010) and allow in-situ recording of GSD characteristics. However, overlapping and buried particles make the use of automated techniques, utilizing photographs, challenging.

The complex arrangements of the particles on the river-bed, such as varied orientations, packing and protrusions also highlight the limitations of using GSD characteristics as a parameter in bedload transport and flow resistance equations. Even the use of a full GSD is not sufficient to fully represent the surface morphology and its effect on the flow field (Nikora et al. 1998; Robert 1988; Robert 1990).

Alternatively, the river-bed surface can be considered as a random field of surface elevations $z(x, y, t)$, where $z$ is the surface height at coordinates $x$ and $y$ at time $t$. Thus, the bed can be represented as a Digital Elevation Model (DEM). Recent research has shown that highresolution DEMs, obtained using various topography measurement technologies, allowed the use of statistical tools such as Probability Distribution Functions (PDFs) and second-order 2D structure functions, to understand the structure of water-worked sand-dunes and gravel-beds and quantify roughness parameters (Aberle et al. 2010; Butler et al. 2001; Friedrich 2010; Goring et al. 1999; Nikora et al. 1998; Robert and Richards 1988). The hydraulic roughness can be described as a scale-dependent set of three coefficients, the longitudinal, the transversal and the vertical roughness, with the vertical roughness represented by the standard deviation of bed elevation (Aberle and Nikora 2006; Cooper and Tait 2009; Nikora et al. 1998; Smart et al. 2004). Appropriate measurement technologies are needed to obtain the random field of bed elevations, $z(x, y, t)$, and thus being able to define the various inherent scales of gravel-bed roughness. More attention has to be given to evaluate the measurement techniques that enable such detailed roughness characterization. 
71 Mainly, three types of remote sensing techniques have been used over the years to obtain 72 DEMs of gravel beds: bed-profilers, laser-scanners and stereo-photogrammetry. Coleman's (1997) laboratory experiments with an acoustic bed-profiler proved that this instrument can be successfully employed to measure submerged topography in a large range of situations. Water depths ranging from 5-mm to 1000-mm were employed, as well as various downstream and transverse sampling distances and adjustable acoustic frequency for different vertical accuracies. The acoustic bed-profiler comprises a sounding probe, which generates ultrasonic waves that reflect off the sediment bed and are received by the probe. The time of passage of sound waves is measured electronically and allows determining the distance of the sediment bed from the probe. Unlike infrared bed-profilers, as in Robert (1988), acoustic bed-profilers allow submerged topography measurement. Flowing water can be employed in some situations, and measurements are theoretically unaffected by suspended sediment of size of the order of the sound wavelength or smaller. Acoustic bed-profilers enable higher spatial resolution than the generally used 10 -mm sampling distance with physical profilers (de Jong 1995; Nikora et al. 1998; Smart et al. 2004). However, regardless of the type of bed-profiler, a significant amount of time is required to obtain fine-scale DEMs over a larger area.

A very high horizontal resolution and vertical accuracy can be achieved by using time-offlight Terrestrial Laser-Scanners (TLSs), also called ground-based LiDAR (light detection and ranging) systems. These scanners find the distance of an object by measuring the round-trip time of a pulse of laser light. Aberle and Nikora (2006), Cooper and Tait (2009) and Goring et al. (1999) conducted bed-elevation measurements in drained laboratory flumes using TLSs. Manufacturer specified vertical accuracies vary from $0.5-\mu \mathrm{m}$ to $0.1-\mathrm{mm}$. Heritage and Hetherington (2007), Hodge et al. (2009) and Smart et al. (2004) conducted surveys with 
TLSs over exposed gravel bars in natural streams. Laser-scanning is the most precise widerange topography measurement device at the moment. However, TLSs' data requires significant post-processing in the form of filtering to remove systematic errors (Hodge et al. 2008). Also, despite the existence of a multitude of laser-scanners, the cost remains high. There is another disadvantage, as some of the TLSs cannot be used for measuring submerged topographies, because of an infrared light pulse absorbed by water (Hodge et al. 2008; Smart et al. 2004).

Similarly to human vision, stereo-photogrammetry makes use of two overlapping 2D images to obtain one depth image within the Common Field of View (CFoV) of the two images. Nowadays, commercially available software packages, such as OrthoMAX from Erdas Imagine ${ }^{\circledR}$, allow high-resolution DEM recording with digital stereo-photogrammetry, from either digital images or digitized film photographs. Those packages are often expensive and limited for specific use. Using OrthoMAX, laboratory-based experiments were carried out by Butler et al. (2001), Brasington and Smart (2003) and Chandler et al. (2001). DEMs of exposed, simulated beds, were plotted onto an adjustable grid, with a sampling distance as small as 1.5-mm. Using ground control points coordinates, Brasington and Smart (2003) and Chandler et al. (2001) assessed surface precision, with standard errors in vertical measurement of 2-mm and 1.1-mm, respectively. Stereo-photogrammetry has the advantage to be relatively easy to set up in both laboratory and field environments, with very quick data acquisition, yet it generally requires special calibration. Field-based applications were carried out by Butler et al. (1998) and Carbonneau et al. (2003), to measure the topography of exposed gravel bars. In addition, Butler et al. (2002) and Westaway et al. (2000; 2001), proved that stereo-photogrammetry can handle through-water measurement, but a rigorous strategy must be employed to assess the quality of the DEMs. Whilst stereo-photogrammetry is to date certainly the most promising technique to remotely sense the dynamic behavior of 
119 gravel-beds at the grain scale, the operational process to obtain DEMs is complex. This

120 generally requires the development of a unique methodology to carefully assess the reliability

121 of the measurements (Butler et al. 1998). Another disadvantage is oblique scanning from two

122 different viewpoints, which causes shadowing behind protruding particles and results in

123 erroneous data in those affected areas.

\section{Objective}

125 Often laboratories have access to one measurement technique for gravel-bed data acquisition.

126 The study's objective is to compare bed-roughness data collected with the above described,

127 most commonly used, three measurement methodologies, which were available for this

128 project. The study is split in two parts, which build upon each other. Initially, a screeded bed

129 was water-worked and once fully developed, the bed was measured with all three available

130 measurement techniques, namely acoustic bed-profiler, laser scanner and stereo-

131 photogrammetry. The water-worked data are used to study the suitability of the DEMs to

132 undertake statistical analysis of the bed roughness and assess the differences in quantitative

133 and qualitative roughness characteristics for the same roughness area, but different

134 measurement methodology. The analysis focuses on the hydraulic roughness, represented by

135 the standard deviation of bed elevations, and bed-elevation Probability Distribution Functions

136 (PDFs) and second-order structure functions (semivariograms) of the DEMs. In order to

137 compare the water-worked roughness characteristics, screeded bed topography, recorded with

138 the acoustic bed-profiler, is assessed.

139 The second part of the study presents the methodological improvements that were made for

140 the stereo-photogrammetric setup, and how those improvements affect the quality of recorded

141 DEMs. 


\section{DATA COLLECTION}

\section{The experimental setup}

144 Data collection was undertaken in the Fluid Mechanics Laboratory of The University of

145 Auckland, using a 19-m long sediment-starved tilting flume, with 0.45-m width and 0.5-m

146 depth. For the presented experiments, the slope of the flume bed was set to 0.45 .

147 Measurements were obtained on a vertically adjustable test section, located 10-m downstream

148 of the flume inlet, comprising of a fixed bed with a 950-mm long and 450-mm wide recess.

149 The recess was filled with graded, rounded and colored gravel (each class of sediment, except

150 the smallest one was painted with a different color, using white, yellow, green, blue and red).

151 The use of painted gravel particles was necessary for a parallel study on cluster formation and

152 sediment tracking. The sediment had a median size of the intermediate particle axis $\mathrm{D}_{50}=7$ -

$153 \mathrm{~mm}$, a minimum sediment size of $0.7-\mathrm{mm}$, a maximum gravel size of 50-mm and a geometric

154 standard deviation of the grain distribution, calculated as $\sqrt{D_{84} / D_{16}}$, of 2.98. To enable

155 topography measurement, the test section was equipped with a horizontal rack for the acoustic

156 bed-profiler, as well as an overhead mounting bar for stereo-photogrammetry equipment, on

157 which two cameras were mounted (Figure 1). The initial screeded bed was created by placing

158 randomly mixed sediment into the base of the vertically adjustable survey area and the surface

159 was flattened to a thickness of $100-\mathrm{mm}$, parallel to the flume bed. The topography of the

160 initial manually screeded bed was measured with the acoustic bed-profiler. The gravel-bed

161 was then water-worked and naturally armored over four hours, at a constant flow rate $Q=66$ -

$162 \mathrm{~L} / \mathrm{s}$, monitored by a pre-calibrated pressure gauge. The water depth was kept constant at 200-

$163 \mathrm{~mm}$, and adjusted using a sharp-edged weir at the downstream end of the flume. A steady

164 uniform flow was maintained throughout the experiment with a Froude number $\mathrm{Fr}=0.58$. 
165 The area used for direct comparison of the three measurement techniques was $0.35-\mathrm{m}$ long

166 and 0.3-m wide (Figure 2). As the laser-scanner could not be used directly at the flume, a

167 metallic tray was submerged into the initially screeded mixture, completely covered by the

168 sediment layer, allowing the careful transportation of the $0.35-\mathrm{m}$ long and $0.3-\mathrm{m}$ wide water-

169 worked gravel-bed sample to the location, where the laser is housed. Whilst water-working,

170 the upper sediment layer eroded downstream. The experiment was stopped just when the tray

171 started to be exposed. Thereafter, the bed topography was measured with the acoustic bed-

172 profiler. The flume was then drained to allow in-air stereo-photogrammetry measurement.

173 Finally, the metallic tray was carefully uncovered and moved to the location of the laser-

174 scanner, to undertake the laser-scanner data collection.

175

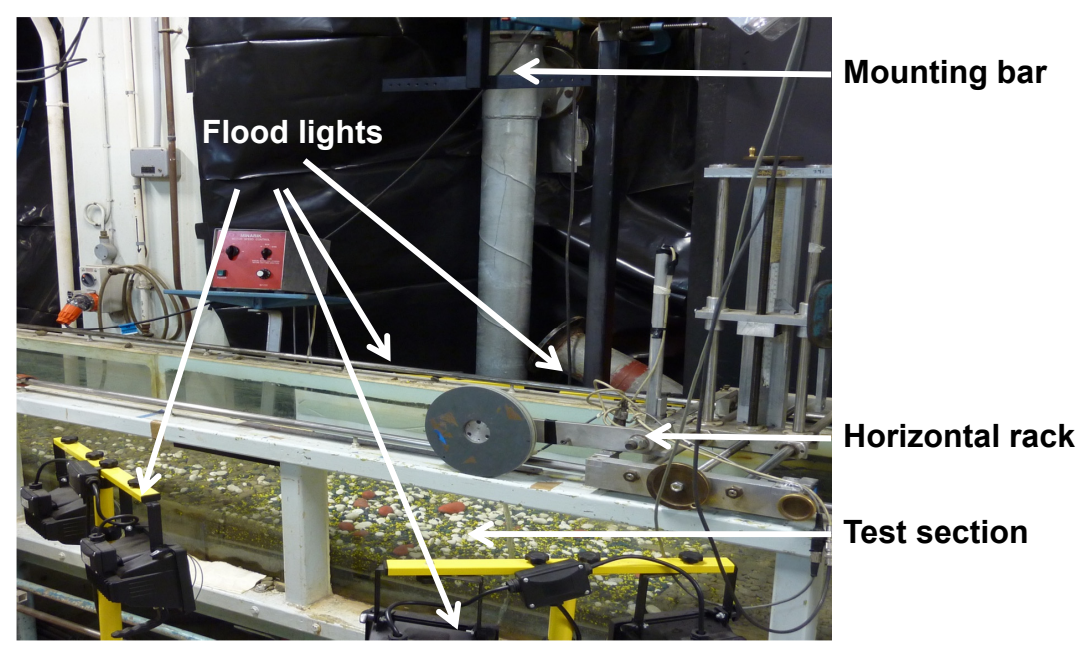

176 Fig. 1. Flume setup

\section{Acoustic bed-profiler}

178 Measurements of the submerged gravel-beds, at initial screeded and final water-worked

179 stages, were undertaken with a reduced flow rate to avoid suspended sediment that could lead

180 to erroneous data. The acoustic bed-profiler is comprised of a sounding probe, located 100-

$181 \mathrm{~mm}$ above the sediment bed, mounted on a rack above the flume, traversing the measurement 
section in flow direction, and an optical potentiometer of 256 increments per revolution,

183 attached to the hub of a $200-\mathrm{mm}$ diameter wheel, tracking the probe location in the

184 downstream direction. With a sound wave of frequency $f=2-\mathrm{MHz}$ it provided a theoretical

185 vertical accuracy of $0.37-\mathrm{mm}$ (see Table 1). 2D longitudinal bed-elevation profiles were

186 acquired and subsequently DEMs were obtained with a sampling distance of 2.45-mm

187 downstream (based on the number of increments on the potentiometer and wheel size) and

188 2.54-mm transverse (0.1-inch on the scale utilized), representing the physical grid over which

189 the measurements were done.

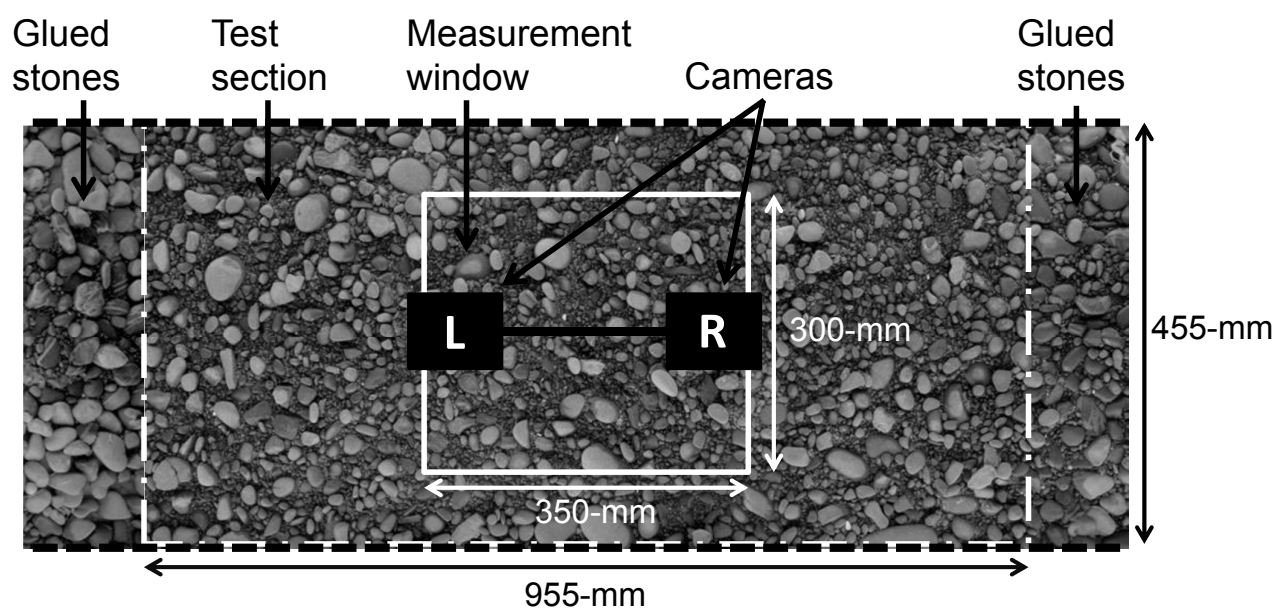

191 Fig. 2. Gravel bed and measurement window

\section{Laser-scanner}

193 The topography of the final water-worked bed, restricted to the area bounded by the edges of

194 the metallic tray, was measured with an Inition MVT CLS60 hand-held laser-scanner,

195 available in The University of Auckland Automated Systems Laboratory. Because of the short

196 arm of the laser, it could not be used directly above the flume and required the transportation

197 of the gravel-bed sample. Once transported, the sample was scanned vertically from a distance

198 of $100-\mathrm{mm}$ by making several overlapping stripes. The theoretical vertical accuracy is

199 quantified as $0.05-\mathrm{mm}$ (manufacturer specified), and data is recorded on a non-uniform spatial 
grid. The merging of the overlapping stripes was operated automatically by the instrument's

201 software, with the process repeated until successful merging was obtained. The laser-scanner 202 has the advantage that both depth and color information are recorded, although color 203 information was not used for this study. Finally, data was saved as an ASCII file and was 204 directly read into MATLAB®. The non-uniform data cloud was transformed to a uniform grid 205 with 1.45-mm sampling distance (Table 1). Measurements took place in non-submerged 206 conditions. However, preliminary tests showed that wet conditions, e.g. with wet particle 207 surfaces, have no detrimental effect on the laser's accuracy (see Table 2).

\section{Stereo-photogrammetry}

209 Stereo-photogrammetric measurements of the exposed water-worked bed were carried out

210 with two Nikon D90 digital consumer cameras, with an $18-\mathrm{mm}$ lens and a $5.5-\mu \mathrm{m}$ pixel pitch 211 (12.3-megapixels). The two cameras were attached on a frame 1-m above the flume, 212 mechanically aligned with a $280-\mathrm{mm}$ baseline between the cameras, using a mounting bar. 213 The settings for both cameras were manually adjusted to be identical (shutter speed of 1.3-s, 214 F/22 aperture, ISO 200) and manually focused on the gravel-bed. The Common Field of View $215(\mathrm{CFoV})$ of the two cameras, chosen to be larger than the test section, defined the area over 216 which depth information was extracted. Initially, stereo images of the calibration 217 checkerboard were taken in various positions inside the hydraulic flume, covering all degrees 218 of freedom and most of the cameras' CFoV (Zhang 1998). Using MATLAB ${ }^{\circledR}$ and Bouguet 219 and Perona's (1998) camera calibration toolbox, the intrinsic parameters of the two cameras 220 (focal length, principal point, skew among others), and the extrinsic parameters of the stereo 221 setup (translation and rotation between the two cameras) were determined. Radial and 222 tangential lens distortion of the two cameras was modeled using a $6^{\text {th }}$ order polynomial. The 223 calibration data enabled the photographs of the gravel-bed to be rectified to epipolar 
geometry, where corresponding points between the left and right images are on the same scan

225 lines, after distortion is removed. From the rectified images of the gravel-bed and the

226 calculated disparity search range, the Symmetric Dynamic Programming Stereo-

227 photogrammetry (SDPS) algorithm allowed getting a map of the bed surface elevations, also

228 called disparity map, within the CFoV (Gimel'farb 2002). A point cloud is extracted, with

229 sampling distance between measured data points representing the pixel size on the gravel-bed

230 images as taken with the Nikon D90s from a distance of 1-m. Finally, the data were

231 transferred to a uniform grid with a sampling distance of 1-mm (Table 1). The best vertical

232 accuracy achievable by the setup in these conditions was calculated as 1-mm.

\section{Improved stereo-photogrammetric setup}

234 The results obtained with stereo-photogrammetry in the first part of the study were not 235 satisfactory, as shown in the 'Results' section. Thus, work was done to obtain better DEMs 236 using photogrammetric means.

237 The following improvements were made, which can be used as a checklist to obtain high238 quality DEMs. Firstly, the measurement section needs to be illuminated as evenly and as best 239 as possible. In addition to placing light sources strategically, any reflection bouncing off the 240 measured object can negatively influence the measurement process. Thus, as a first step, the 241 light sources outside the flume were changed from initially four flood lights to two 1-m long 242 neon lights, which were placed behind a dissipative sheet, resulting in a homogeneous 243 illumination of the measurement area. Secondly, the painted gravels were replaced by natural 244 gravel particles, eliminating any reflection bouncing off the gravel-bed. The third change was 245 to resize the $\mathrm{CFoV}$, by reducing the distance from the cameras to the gravel bed. This change 246 is not responsible in its own for the reduction of streaks and noise in the DEMs, but it led to 247 an enhanced vertical accuracy of $0.34-\mathrm{mm}$ (see Table 1). In addition, the measurement 
248 resolution increased to approximately 30.8-million points $/ \mathrm{m}^{2}$, equivalent to $0.18-\mathrm{mm}$ pixel 249 size on the gravel-bed surface. Fourthly, a modified checkerboard was used. The 250 checkerboard used previously was made of plastic, and was a cause of light reflection. It did 251 not always allow correct corner recognition during the calibration process leading to 252 inaccurate calibration parameters. Finally, the frame mounting bar holding the cameras was 253 adjusted to allow a faster and more accurate calibration process. The cameras' mounting bar 254 could be rotated at $90^{\circ}$, allowing photographs of the checkerboard to be taken with the 255 checkerboard mounted on a tripod outside the flume.

256 A simple MATLAB ${ }^{\circledR}$ program was developed to evaluate the accuracy of the calibration step, 257 based on the reprojection error. Using the calibration results (summarized in the projection 258 matrices of the two cameras), the estimated corners of the checkerboard, originally in 3D 259 world coordinates, can be reprojected onto the 2D calibration images. The estimated corners 260 are compared with the actual corners detected with the subpixel corner detection algorithm 261 available with $M A T L A B \AA$. The reprojection error, in pixel, is defined as the difference 262 between the actual corners and the estimated corners. A decrease in reprojection error shows 263 that the calibration parameters (both intrinsic and extrinsic) are better estimated. In the 264 absence of an external assessment of DEMs quality, an internal assessment of the calibration 265 step was undertaken to contrast two DEMs obtained with stereo-photogrammetry.

\section{Data post-processing}

267 The same data post-processing procedure was applied to all DEMs obtained in the first part of 268 the study. The DEM obtained with the improved stereo-photogrammetric setup (Figure 5), 269 forming the second part of the study, was of high quality, with no spikes observed and the

270 following data post-processing procedure was not needed. Data post-processing consisted of 271 removing measurement spikes and interpolating gaps. Spikes, which were outside the 
minimum/ maximum bed elevations, as found with the acoustic bed-profiler DEM $\pm 2-\mathrm{mm}$, were removed. Minor spikes, due to measurement imprecision and noise, were automatically detected as data points lying outside their four neighbors' elevation, allowing for a $\pm 3-\mathrm{mm}$ threshold. The threshold of 3-mm is specific to the used sediment mixture and was obtained

276 through manual testing. The gaps generated by the removal of spikes were automatically 277 filled by the average elevation of the four neighboring data points.

278 Before analyzing the DEMs statistically, a detrending algorithm was applied on each DEM. 279 Surface detrending aims to remove larger scale trends than the grain-scale, such as bed slopes, 280 which could obscure DEMs properties and bias grain roughness statistics. This also removes 281 any deviation of the measurement instruments from a parallel positioning to the sediment bed. 282 In accordance with Andreas and Trevino (1997), and Goring et al. (1999), a second-order 283 biquadratic removing filter was applied, as this reduced the variance of the original data series 284 the most. The difference in variance between the original and the detrended signals was 285 significant, and exceeded the square of the measurement resolutions. Finally, all DEMs were 286 normalized to have a mean bed elevation equal to zero, and rotated in order to align the DEMs 287 with the flow direction.

\section{STATISTICAL ROUGHNESS ANALYSIS}

289 Statistical roughness analysis serves as the basis for the comparison of the employed 290 measurement techniques and whether the obtained DEMs (Figure 4) warrant to be used for 291 future studies on gravel-bed roughness characterization. Initially, Probability Distribution 292 Functions (PDFs) were obtained, representing the distribution of surface elevations. 293 Parameters like skewness, kurtosis and standard deviation of surface elevations were 294 extracted from the detrended surfaces. Similar to previous work by Aberle and Nikora (2006), 
295 Cooper and Tait (2009) and Nikora et al. (1998), the vertical roughness height was estimated using the standard deviation of the bed elevation $\sigma_{z}$.

297 In addition, generalized second-order 2D structure functions were used, defined by Nikora et 298 al. (1998) in discrete form as:

$$
\begin{aligned}
D_{G 2}(\Delta x, \Delta y)= & \frac{1}{(N-n)(M-m)} \sum_{i=0}^{N-n} \sum_{j=0}^{M-m}\left\{\mid z\left(x_{i}+n \delta x, y_{j}+m \delta y\right)\right. \\
& \left.-z\left(x_{i}, y_{j}\right) \mid\right\}^{2}
\end{aligned}
$$

where, $\Delta x=n \delta x$ and $\Delta y=m \delta y ; \delta x$ and $\delta y$ are sampling intervals in the longitudinal and transverse directions respectively; $n=1,2,3, \ldots N$ and $m=1,2,3, \ldots M . N$ and $M$ are the number of samples in the same two directions. The relationship in Eq.1 is used to represent the generalized 1D second-order structure functions, as well as isopleth maps (contour plots) of the $2 \mathrm{D}$ structure functions. To enable a direct comparison between the various measurement techniques, the structure functions were normalized with the 'saturation level' $2{\sigma_{z}}^{2}$ and the contours of $D_{G 2}$ were plotted as proportions of the saturation level.

The irregular nature of gravel-bed profiles suits the use of generalized structure functions to investigate the fractal properties of the bed surface, which provides information about the inherent scales of roughness present on the gravel-bed surface. A structure function has three regions: a scaling region with uniform slope at small lags, a saturation region at large lags, 312 where the slope is zero, with a transition region in between, where the slope decreases (Butler 313 et al. 2001; Goring et al. 1999; Nikora et al. 1998; Robert and Richards 1988).

314 At small spatial lags, the scaling region can be fitted by a power function of the form $315 D(\Delta x) \propto \Delta x^{2 H_{x}}$ (Figure 7a) and $D(\Delta y) \propto \Delta y^{2 H_{y}}$ (Figure 7b). Butler et al. (2001) and Robert 316 (1988) showed that when plotted in log-log scale, the use of a power function allows the 317 determination of the directional Hurst exponents $H_{x}$ and $H_{y}$, representing a basic method to 
318 estimate the fractal dimension of series of data along the downstream and transverse 319 directions, respectively. They also showed that the directional fractal dimensions of series of 320 points, also called Hausdorff dimensions, can be estimated from the slopes of the linear parts 321 of the structure function, using the relation $2-H$ and can be linked to different roughness 322 scales.

\section{RESULTS}

\section{Digital Elevation Models (DEMs)}

325 Both, the initial screeded and final water-worked beds, were measured with the acoustic bed326 profiler over the complete recess section (Figure 3). The manually screeded bed (Figure 3a) is composed of grains of different sizes with buried bigger particles. The surface is flat and uniform, with bed elevations between $-12.3-\mathrm{mm}$ and $7.2-\mathrm{mm}$, and sediment randomly distributed. In contrast, the water-worked bed (Figure 3b) presents a heterogeneous surface,

330 with a larger range of bed elevations, of $-24.4-\mathrm{mm}$ to $29.7-\mathrm{mm}$. The surface, composed of 331 coarse grains, with small particles filling the holes between them, presents the evidence of 332 armoring. In Figure 3b, the edges of the metallic tray are clearly visible, defining the region over which the statistical analyses were conducted.

334 The DEMs of the water-worked bed vary notably (Figure 4). With the acoustic bed-profiler, 335 the surface appears smooth with little noise (Figure 4a). Any visible errors are concentrated 336 on the particles' edges, where major elevation changes occur rapidly. The laser-scanner's 337 DEMs (Figure 4b) are similar to those obtained with the acoustic bed-profiler. Although, 338 theoretically, the higher resolution of the laser scanner should enable the edges of the particles 339 to be more representative, this is not observed, due to measurement noise. The DEM obtained 340 with stereo-photogrammetry (Figure 4c) is of least quality, despite the highest resolution. Not 
341 all of the major gravel particles are well captured. Detailed inspections also show major noise,

342 even after despiking, thus prompting us to investigate the cause of the noise further, which

343 resulted in the methodological changes made on the photogrammetric setup presented in

344 section 'Improved stereo-photogrammetric setup'. The changes led to a decreased 345 reprojection error. The obtained DEM presented in Figure 5 used calibration results with a 346 standard deviation in reprojection error of 0.2-pixels, compared to the reprojection error for 347 the DEM of Figure 4c with a standard deviation of 1.15-pixels. The measurement noise is 348 correctly suppressed by an improved photogrammetric process, and all particles on the gravel349 bed surface are correctly represented. Consequently, the decreased reprojection error results in 350 a visually appealing DEM (Figure 5), plotted on a very fine grid, with 0.2-mm sampling 351 distance.

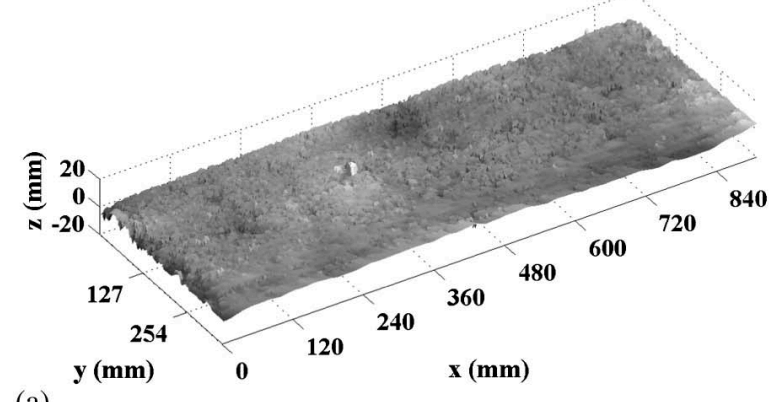
(a)

Fig. 3. Detrended DEMs obtained with the acoustic bed profiler in submerged conditions,

354 after despiking, for (a) the initial screeded bed; (b) the final water-worked bed

\section{Probability Distribution Functions (PDFs)}

356 PDFs were generated to allow a statistical comparison of texture parameters for the various 357 measurement techniques, such as skewness, kurtosis, range of elevations, and the vertical 358 roughness length. In addition, it is a useful tool for comparing initial screeded and final water359 worked beds and studying the influence of armoring. 

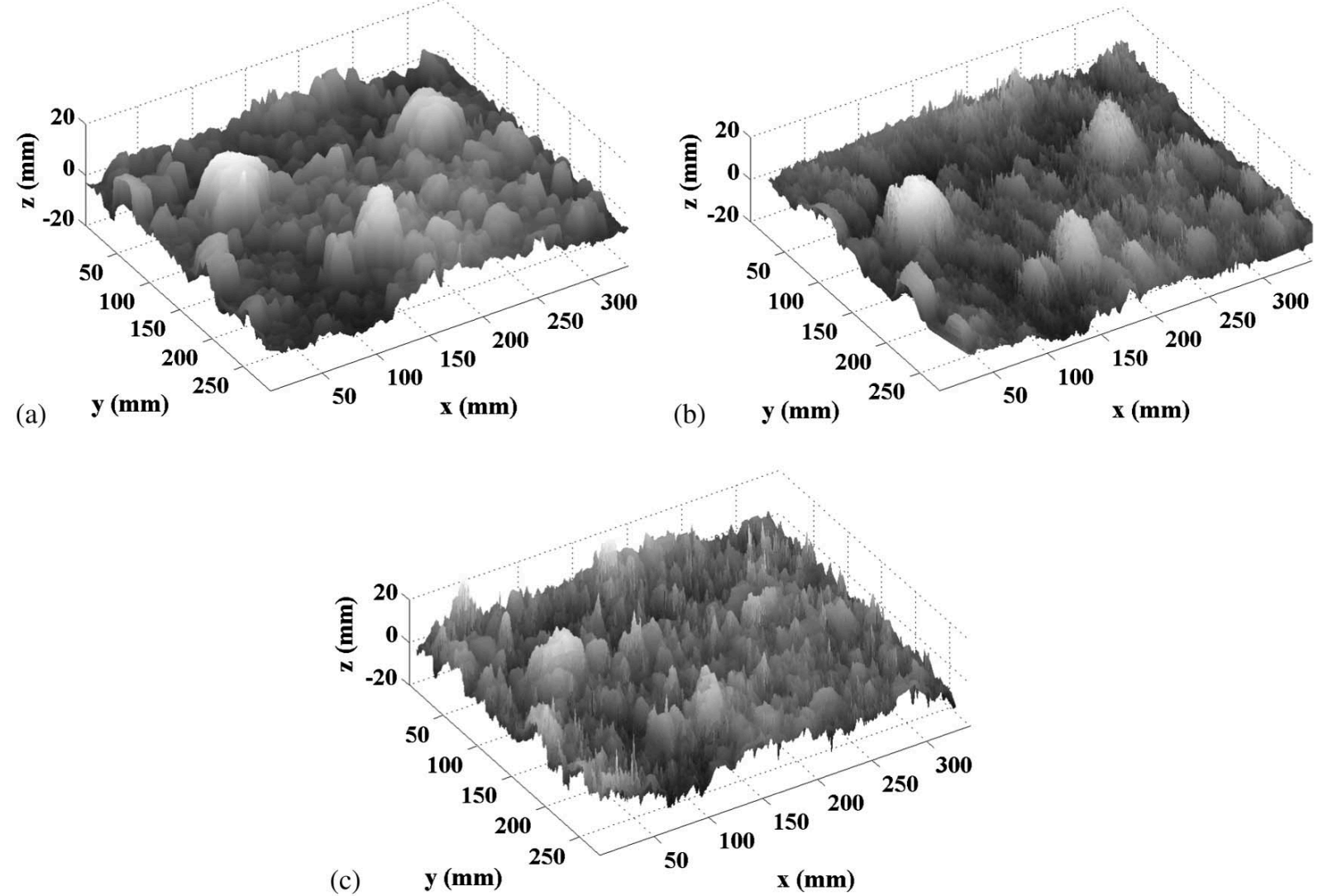

361 Fig. 4. Detrended DEMs of the water-worked bed, after despiking, focused on the region

362 within the metallic tray, obtained with (a) the acoustic bed profiler; (b) the laser scanner (dry

363 condition); (c) stereophotogrammetry

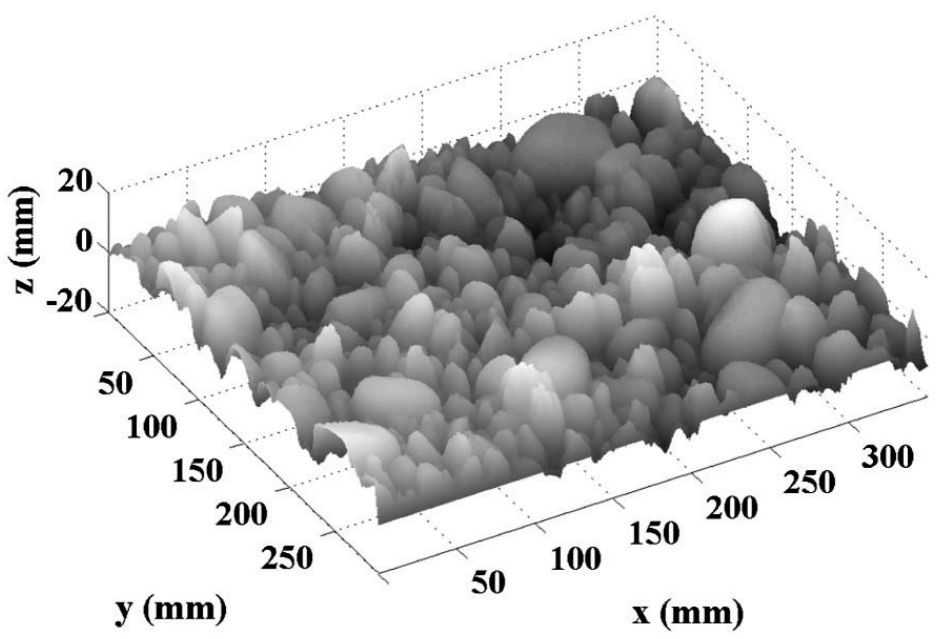

365 Fig. 5. DEM of a water-worked bed obtained with the improved stereophotogrammetric setup 
In accordance with previous studies, e.g. Aberle and Nikora (2006) and Cooper and Tait

367 (2009), the initial screeded bed is negatively skewed (Figure 6a), whereas the water-worked

368 beds are positively skewed (Figures $6 \mathrm{~b}-\mathrm{c}-\mathrm{d}$ ), for all three measurement techniques. The PDFs

369 of Figure 6 also visualize the augmentation of geometrical roughness during the armor layer

370 development, i.e. the augmentation of particles of higher elevations with respect to the mean

371 bed level, which protrude into the flow. A larger range of bed elevations is observed for a

372 water-worked bed (Figures 6b-c-d), compared with the narrower range for a screeded bed

373 (Figure 6a). As Table 2 shows, after water-working the initially screeded gravel-bed, the

374 skewness coefficient and the standard deviation of the bed elevation, $\sigma_{Z}$, increase, and

375 characterize the coarsening of the gravel-bed surface. No significant change in the kurtosis

376 value was observed.
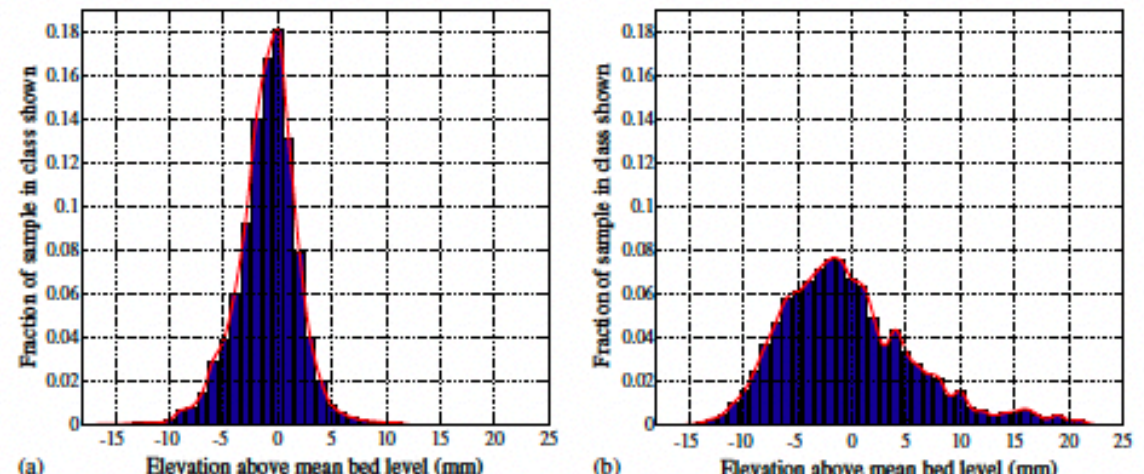

(a)

Elevation above mean bed level (mm)

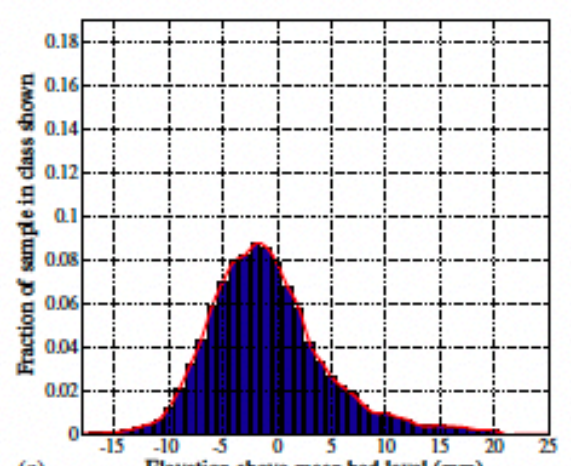

(c)

Elevation above mean bed level $(\mathrm{mm})$

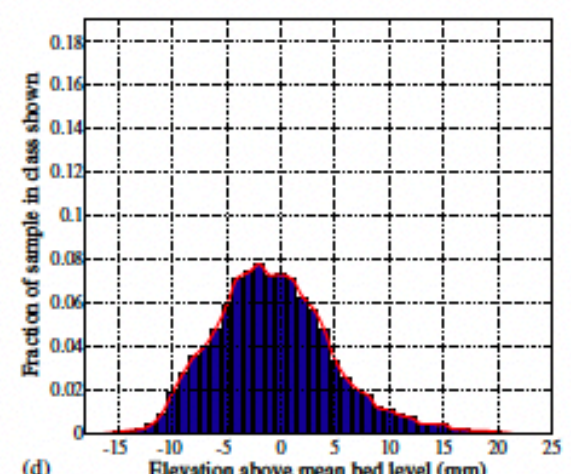

(d)

Fig. 6. PDFs obtained with (a) the acoustic bed profiler over the screeded bed, and over the restricted water-worked bed with (b) the acoustic bed profiler; (c) the laser scanner (dry condition); (d) stereophotogrammetry 
381 For laser-scanner DEMs, similar statistics for the dry and wet surfaces are obtained, indicating

382 a good reproducibility of the results. Although, statistically, the DEM obtained with the initial 383 stereo-photogrammetric setup, results in a reduced skewness and roughness length, the 384 statistics do not vary to the extent, as the visible DEM shortcomings would suggest. The 385 statistics of the DEM obtained with the improved stereo-photogrammetric setup, as obtained 386 in the second part of the study, are not presented, as the studied water-worked gravel-bed is 387 different. Figures 6b-c-d show that the range of bed elevations is similar for all three DEMs, 388 but the distribution of bed elevations in the different ranges varies. The DEM obtained with 389 the acoustic bed-profiler presents the lowest sorting in bed elevations, with the smallest 390 fraction of bed elevations around the zero mean-bed level. Noise present in the DEMs 391 obtained with the laser-scanner and the initial stereo-photogrammetric setup causes more 392 particles to be distributed around the zero-mean and less particles at low and high elevations.

\section{Second-order structure functions}

394 Previous research showed that the value of the Hurst exponent is inversely proportional to the 395 degree of complexity of the gravel-bed surface (Aberle and Nikora 2006; Cooper and Tait 396 2009; Nikora et al. 1998). For our study, the screeded bed has a smaller Hurst exponent than 397 the water-worked bed, which suggests that the screeded bed surface, with numerous smaller 398 bed elevations, is more complex than the water-worked bed, which comprises a larger range 399 of bed elevations (Figure 7). This correlates well with previous experiments of Aberle and 400 Nikora (2006), where Hurst exponents of the man-made screeded beds are smaller than those 401 of water-worked beds, with Hurst exponents increasing with increasing discharge.

402 The scaling region of the structure function provides information about the horizontal 403 roughness indices, which can be determined from the slope breakpoint, located at the 404 intersection between the tangent to the scaling region slope and the saturation level 
406 for water-worked beds, than for screeded beds (Figure 7). The sediment particles on the bed

407 surface coarsen during water-work.

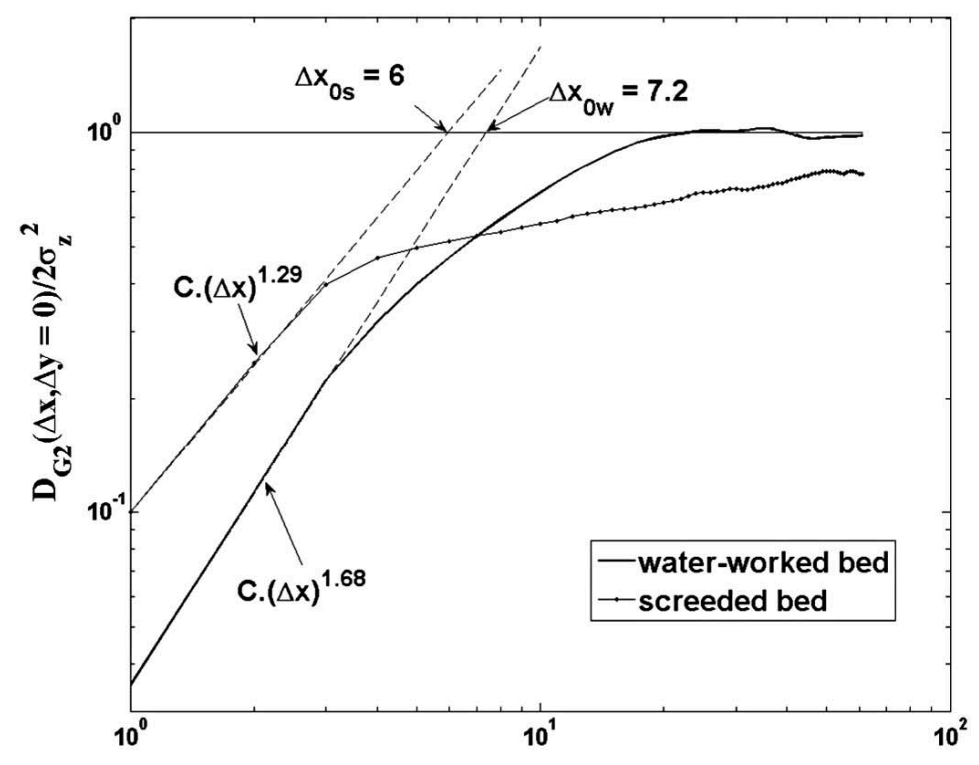

(a)

$\Delta \mathbf{x}(\mathbf{m m})$

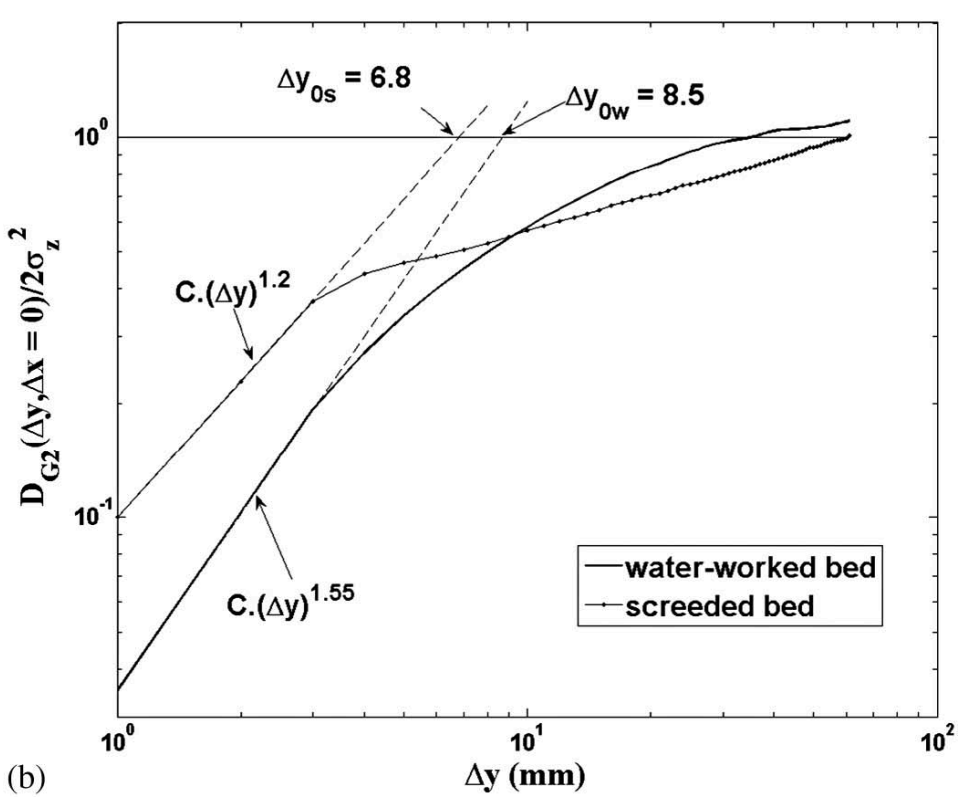

409 Fig. 7. Generalized second-order structure functions plot in a log-log scale, for (a) $\Delta y=0$; (b)

$410 \Delta \mathrm{x}=0$

411 As presented by Aberle and Nikora (2006) and Friedrich (2010), the use of isopleth maps of

412 2D structure functions provides useful information on the surface forming mechanisms during 
413 the armor layer development. Contour lines at small spatial lags are circular for the screeded

414 bed (Figure 8a), indicating isotropy of the surface structure and a random organization,

415 whereas the contour lines of all water-worked beds are characterized at small spatial lags by

416 an elliptical shape (Figure 8b-c-d). This finding agrees with previous work by Aberle and

417 Nikora (2006), Cooper and Tait (2009) and Goring et al. (1999). Geometrically, the elliptical

418 shape of the contour lines reflects the general elliptical form of the dominant particles and an

419 anisotropic surface structure of the bed. In this study, particles rotate to align their long axis

420 across the flow direction (Figure 8b-c-d), as observed also by Goring et al. (1999).
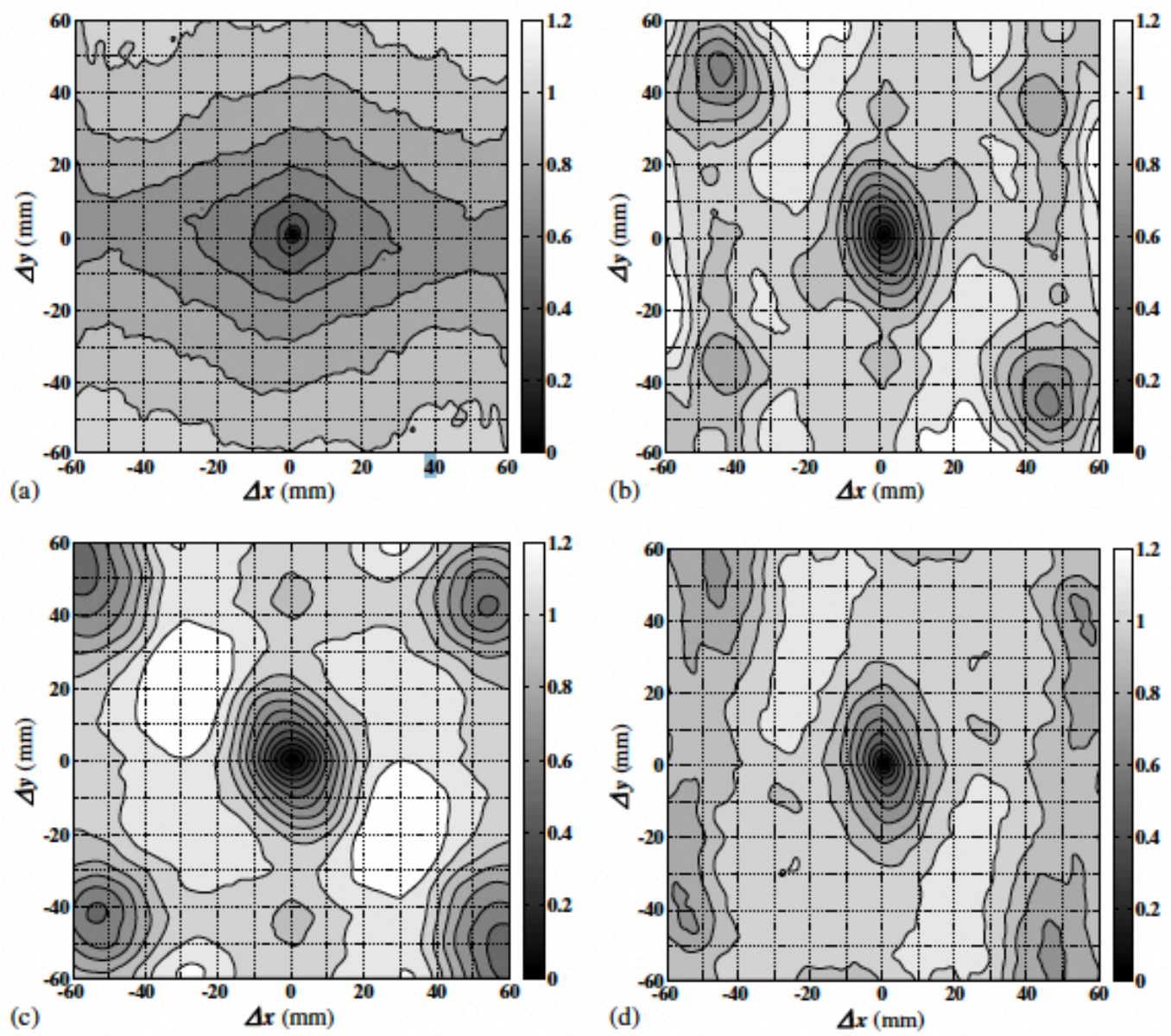

422 Fig. 8. Contour lines of structure functions obtained with (a) the acoustic bed profiler over the

423 screeded bed, and over the restricted water-worked bed with (b) the acoustic bed profiler; (c)

424 the laser scanner (dry condition); (d) stereophotogrammetry 
426 The three measurement technologies employed in this study, theoretically allow grain-scale 427 elevation measurements of water-worked beds in a laboratory flume. In their work, Lane et al. 428 (1994) estimated that between 4,000 and 10,000-points $/ \mathrm{m}^{2}$ (equivalent to $10-\mathrm{mm}$ to $16-\mathrm{mm}$ 429 sampling distance) are necessary to survey the morphology of a braided proglacial stream at 430 the grain scale. In the first part of our laboratory study, utilizing sediment with $\mathrm{D}_{50}=7-\mathrm{mm}$, 431 DEMs with resolutions between 160,000 and 1,000,000-points $/ \mathrm{m}^{2}$ (equivalent to $1-\mathrm{mm}$ to 432 2.54-mm sampling distance) were obtained. For the $0.35-\mathrm{m}$ long and $0.3-\mathrm{m}$ wide 433 measurement window, this equates to approximately 16,870 data points for DEMs obtained 434 with the acoustic bed-profiler. DEMs with around 49,940 and 105,000 data points were 435 obtained for the laser-scanner and initial stereo-photogrammetric setup, respectively. Our 436 statistical analysis showed that the measurement resolution is not the only key parameter 437 when comparing the quality of the DEMs. The initial stereo-photogrammetric setup had the 438 highest measurement resolution, with statistics showing only a minor deviation from the other 439 DEMs, but visual observation of the DEM showed substantial shortcomings (Figure 4c). 440 Problems were encountered with the reflection of the painted gravel particles, causing 441 inaccuracies in creating the map of the bed surface elevations, and thus resulting in spikes in 442 the DEM. Compared to the other two measurement techniques, stereo-photogrammetry 443 requires a multi-stage recording process (calibration of cameras, creating depth map, 444 extracting point cloud), with errors of various stages accumulating. Calibration inaccuracies 445 for the initial stereo-photogrammetric DEM (Figure 4c), prevented the correct rectification of 446 the gravel-bed stereo pairs to epipolar geometry. With stereo-photogrammetry, the recording 447 time was the quickest of all techniques once the cameras were calibrated, which required 30448 minutes (to obtain photographs of the checkerboard and extract the calibration parameters in 449 MATLAB $\left.{ }^{\circledR}\right)$. Calibration results could then be utilized to rectify all images of the gravel-bed 
acquired with the same setup, i.e. when no changes were made on the cameras parameters or

451 the setup geometry.

452 The laser-scanner is theoretically the most accurate measurement instrument for this study, 453 with a theoretical vertical accuracy of $0.05-\mathrm{mm}$. Laser scanning enabled a fast survey of the 454 measurement window. However, the size of the latter was restricted by the laser arm. It also 455 required the transportation of the gravel sample to the location of the laser, and required 456 merging of scanned areas, as it was not able to scan the whole measurement window in one scan. Spikes were encountered during the merging process, which had to be removed 458 automatically, but measurement noise remained, reducing the quality of the final DEM.

459 Finally, the acoustic bed-profiler measured the bed elevation with a theoretical vertical 460 accuracy of $0.37-\mathrm{mm}$. It was the most straightforward measurement equipment to use and was 461 the only technique in our study that enabled measurement of the submerged gravel-bed. 462 During water-working, sediment of sizes larger than 2-mm were transported in suspension, 463 thus requiring to halt the experiment during measurements, to ensure no suspended sediment 464 particles were picked up by the recording. The recording time was the longest of the three 465 studied techniques, which can be a significant drawback when successive DEMs have to be 466 obtained of evolving processes.

467 Visually, DEMs obtained with the acoustic bed-profiler and the laser-scanner seemed well 468 suited for statistical roughness analysis, whereas the DEM obtained with the initial stereo469 photogrammetric setup showed an obvious lack of topographical accuracy. Following the 470 visual study of the DEMs, the DEMs underwent statistical roughness analysis. The vertical 471 roughness length, as expressed with the standard deviation of bed elevations $\sigma_{Z}$, is similar for 472 all DEMs (see Table 2). It was found $\sigma_{Z}=5.36 \pm 0.4$. As observed visually, the grains' 473 edges were not represented accurately in the DEM obtained with the acoustic bed-profiler, 
474 resulting in flatter gravel tops and thus overestimate the standard deviation of bed elevation.

475 The laser-scanner allowed a good reproducibility of the results when tested over a dry and wet 476 gravel-bed surface, as seen in Table 2.

477 Statistical results of the PDFs and generalized second-order structure functions, as presented 478 in Figures 6, 7 and 8, show a good agreement for the various DEMs. This indicates that 479 although visible differences in the topography of the DEMs were observed, those 480 measurement differences are less identifiable when DEMs are described statistically.

481 Our evaluation study highlights that a detailed visual validation of the DEMs is crucial for 482 gravel-bed studies, as significantly different DEMs of the same topography can produce 483 similar roughness statistics. Quantitative validation of DEMs quality can only be made 484 through comparison of obtained bed elevations with a ground truth, which is often practically 485 not feasible, as in our presented study. In our study, the laser-scanner was theoretically the 486 most accurate instrument, but noise in the DEM prevented using the laser-scanner data as a 487 ground truth. Other studies evaluate the error rate of one measurement technique by 488 comparing several records with each other, like it was done in studies employing stereo489 photogrammetry (Butler et al. 1998; Carbonneau et al. 2003; Chandler et al. 2001).

490 The obtained initial stereo-photogrammetric DEM was of inferior quality (Figure 4c) and 491 prompted additional testing to obtain high-quality DEMs, as the literature research showed 492 that low-cost stereo-photogrammetric measurements of gravel-bed topographies will be useful 493 for future studies. In previous hydraulic applications of stereo-photogrammetry, semi-metric 494 cameras were used (Butler et al. 1998; Butler et al. 2001; Butler et al. 2002), in addition to 495 commercial photogrammetric software (Brasington and Smart 2003; Butler et al. 1998; 496 Carbonneau et al. 2003; Chandler et al. 2001; Rapp et al. 2012; Westaway et al. 2001). The 497 calibration technique relied on automatic block-bundle adjustment, or self-calibration 
technique. Targets were required, generally a large number, to be arranged on the surface to

499 survey. The 3D locations of the targets are determined with Leica total stations, making for 500 the duplicity of measurement instruments in the experiments and increasing the chance of 501 errors propagating. In addition, targets glued on the riverbed surface disturb the experiment 502 and are not complementary with an otherwise remotely sensed topography.

503 In our low-cost stereo-photogrammetric setup, we decide to use Zhang calibration technique 504 (Zhang 1998), which requires a planar calibration pattern (called checkerboard) to be 505 photographed in several positions. Although it requires additional time to obtain these images, 506 this calibration technique avoids using ground control points disposed on the riverbed. It is 507 also considered that Zhang calibration will be more suitable for field work, where the areal 508 coverage is larger than inside laboratory flumes, which would mean that more targets are 509 required, compared to a laboratory study. Using ground control points, measured with total 510 stations, has however the advantage that it provides information to assess externally the 511 DEM's quality. With our proposed low-cost stereo-photogrammetric setup, a simple 512 MATLAB ${ }^{\circledR}$ program was prepared to evaluate the accuracy of the calibration step, which was 513 identified as a source of error for the DEMs. The evaluation is based on the reprojection error. 514 Following the checklist provided in section 'Improved stereo-photogrammetric setup' results 515 in a decreased reprojection error, which in turn enables a high-quality DEM to be obtained 516 (Figure 5).

517 Besides exhibiting the best accuracy qualitatively, the DEM obtained with the improved 518 stereo-photogrammetric setup has a sampling distance of $0.2-\mathrm{mm}$ on the gravel-bed surface, 519 which corresponds to the highest DEM resolution so far obtained for gravel-bed studies, 520 compared to the previous minimum of 1-mm obtained by Cooper and Tait (2009) with TLS 521 and by Carbonneau et al. (2003) with stereo-photogrammetry. 


\section{CONCLUSION}

523 A laboratory study to evaluate available measurement techniques to study the hydraulic

524 roughness for gravel beds is presented. The use of an acoustic bed-profiler, a hand-held laser525 scanner and stereo-photogrammetry allowed acquisition of DEMs. Analysis techniques, such 526 as determination of the vertical roughness heights, PDFs and generalized second-order 527 structure functions, are used to study the random field of bed elevations, as represented by the 528 DEMs. The advantages and disadvantages of the three measurement techniques in use are 529 discussed, as well as their suitability for obtaining DEMs for statistical roughness analysis.

530 The results show that all three measurement techniques used for this study are capable of

531 recording DEMs with sampling distances small enough to examine an evolving gravel-bed at 532 the grain scale in laboratory conditions, using a sediment mixture with $\mathrm{D}_{50}=7-\mathrm{mm}$. Statistical 533 analysis resulted in describing vertical as well as horizontal roughness characteristics.

534 Although, visually, differences in the DEMs obtained with different measurement techniques 535 are observed, the results of the chosen statistical analysis do not disclose the visual differences 536 to the same extent.

537 The accuracy of the DEM obtained with stereo-photogrammetry in the first part of this study

538 is inferior to the DEMs obtained with the other techniques, which did not agree with what is 539 theoretically achievable with a stereo-photogrammetric system. We thus presented changes 540 made in the setup, resulting in the highest gravel-bed DEM resolution obtained with stereo541 photogrammetry, 25-million points $/ \mathrm{m} 2$. The result warrants further research into setting up 542 non-proprietary stereo-photogrammetric systems for sediment transport studies. Work is 543 needed to prepare a gravel-bed ground truth to quantitatively validate the DEM's accuracy

544 obtained with the non-proprietary stereo-photogrammetric system. The next step is to employ 
and validate the system underwater, and obtain DEMs to study the dynamic behavior of

546 gravel-beds at the grain-scale.

547

548

549

550

551

552

553

\section{ACKNOWLEDGEMENTS}

Photogrammetric application was conducted in collaboration with the Department of Computer Science, The University of Auckland. We would like to thank in particular Patrice Delmas, Alfonso Gastelum Strozzi and Edwin Chan for their valuable input in obtaining the stereo-photogrammetric data. Laser scanning was undertaken with the help of the Department of Mechanical Engineering, The University of Auckland. We would like to thank Katherine Heays, who introduced the first author to the lab environment. The Fluid Mechanics Laboratory technicians Geoff Kirby and Jim Luo helped in conducting the experiments.

\section{REFERENCES}

Aberle, J., and Nikora, V. (2006). "Statistical properties of armored gravel bed surfaces." Water Resour. Res., 42, W11414.

Aberle, J., Nikora, V., Henning, M., Ettmer, B., and Hentschel, B. (2010). "Statistical characterization of bed roughness due to bed forms: A field study in the Elbe River at Aken, Germany." Water Resour. Res., 46, W03521.

Andreas, E. L., and Trevino, G. (1997). "Using wavelets to detect trends." J. Atmos. Ocean. Tech., 14(3), 554-564.

Bouguet, J.-Y., and Perona, P. (1998). "Camera calibration from points and lines in dualspace geometry." Technical report, California Institute of Technology, 1-16.

Brasington, J., and Smart, R. M. A. (2003). "Close range digital photogrammetric analysis of experimental drainage basin evolution." Earth Surf. Proc. Land., 28(3), 231-247.

Bunte, K., and Abt, S. R. (2001). "Sampling surface and subsurface particle-size distributions In wadable gravel- and cobble-bed streams for analyses in sediment transport, hydraulics, and streambed monitoring." Gen. Tech. Rep. RMRS-GTR-74, U.S. Dept. of 

Agriculture, Forest Service, Rocky Mountain Research Station, Fort Collins, CO, 1428.

Butler, J. B., Lane, S. N., and Chandler, J. H. (1998). "Assessment of DEM quality for characterizing surface roughness using close range digital photogrammetry." Photogramm. Rec., 16(92), 271-291.

Butler, J. B., Lane, S. N., and Chandler, J. H. (2001). "Characterization of the structure of river-bed gravels using two-dimensional fractal analysis." Math. Geol., 33(3), 301330.

Butler, J. B., Lane, S. N., Chandler, J. H., and Porfiri, E. (2002). "Through-water close range digital photogrammetry in flume and field environments." Photogramm. Rec., 17(99), 419-439.

Carbonneau, P. E., Lane, S. N., and Bergeron, N. E. (2003). "Cost-effective non-metric closerange digital photogrammetry and its application to a study of coarse gravel river beds." Int. J. Remote Sens., 24(14), 2837-2854.

Chandler, J., Shiono, K., Rameshwaran, P., and Lane, S. (2001). "Measuring flume surfaces for hydraulics research using a Kodak DCS460." Photogramm. Rec., 17(97), 39-61.

Chang, F. J., and Chung, C. H. (2012). "Estimation of riverbed grain-size distribution using image-processing techniques." J. Hydrol., 440-441, 102-112.

Clifford, N., Robert, A., and Richards, K. ( 1992). "Estimation of flow resistance in gravelbedded rivers a physical explanation of the multiplier of roughness length." Earth Surf. Proc. Land., 17(2), 111-126.

Coleman, S. E. (1997). "Ultrasonic measurement of sediment bed profiles." Proc., 27th Congress of the International Association for Hydraulic Research, San Francisco, California, USA, 221-226.

Cooper, J. R., and Tait, S. J. (2009). "Water-worked gravel beds in laboratory flumes - a natural analogue?" Earth Surf. Proc. Land., 34(3), 384-397.

de Jong, C. (1995). "Temporal and spatial interactions between river bed roughness, geometry, bedload transport and flow hydraulics in mountain streams - examples from Squaw Creek (Montana, USA) and Lainbach/Schmiedlaine (Upper Bavaria, Germany)." Ph.D. thesis, Free Univeristy of Berlin, Berlin.

Detert, M., and Weitbrecht, V. (2012). "Automatic object detection to analyze the geometry of gravel grains." Proc., River Flow 2012, Taylor and Francis Group, San Jose, Costa Rica, 6. 
603

604

605

606

607

608

609

610

611

612

613

614

615

616

617

618

619

620

621

622

623

624

625

626

627

628

629

630

631

632

633

634

Fehr, R. (1987). "Geschiebeanalysen in Gebirgsfluessen; Umrechnung und Vergleich von verschiedenen Analyseverfahren." Mitteilung Nr. 92 der Versuchsanstalt für Wasserbau, Hydrologie und Glaziologie, Eidgenoessischen Technischen Hochschule Zürich.

Friedrich, H. (2010). "Evaluation of statistical analysis techniques for developing bedforms recorded in 3D." Ph.D. thesis, The University of Auckland, Auckland.

Gimel'farb, G. (2002). "Probabilistic regularisation and symmetry in binocular dynamic programming stereo." Pattern Recogn. Lett., 23(4), 431-442.

Goring, D. G., Nikora, V. I., and McEwan, I. K. (1999). "Analysis of the texture of gravelbeds using 2-D structure functions." Proc., I.A.H.R. Symposium on River, Coastal and Esturine Morphodynamics, Genova, Italy, 111-120.

Graham, D. J., Rollet, A. J., Piégay, H., and Rice, S. P. (2010). "Maximizing the accuracy of image-based surface sediment sampling techniques." Water Resour. Res., 46(2), 15.

Heritage, G., and Hetherington, D. (2007). "Towards a protocol for laser scanning in fluvial geomorphology." Earth Surf. Proc. Land., 32(1), 66-74.

Hodge, R., Brasington, J., and Richards, K. (2008). "In situ characterization of grain-scale fluvial morphology using Terrestrial Laser Scanning." Earth Surf. Proc. Land., 34(7), 954-968.

Hodge, R., Brasington, J., and Richards, K. (2009). "Analysing laser scanned digital terrain models of gravel bed surfaces: linking morphology to sediment transport processes and hydraulics." Sedimentology, 56(7), 2024-2043.

Lane, S. N., Richards, K. S., and Chandler, J. H. (1994). "Developments in monitoring and modelling small-scale river bed topography." Earth Surf. Proc. Land., 19(4), 349-368.

Nikora, V. I., Goring, D. G., and Biggs, B. J. F. (1998). "On gravel-bed roughness characterization." Water Resour. Res., 34(3), 517-527.

Rapp, C., Eder, K., and Stilla, U. (2012). "3D determination of the evolution of a scour hole by photogrammetric means." Proc., River Flow 2012, Taylor \& Francis Group, San Jose, Costa Rica, 943-950.

Robert, A. (1988). "Statistical properties of sediment bed profiles in alluvial channels." Math. Geol., 20(3), 205-225.

Robert, A. (1990). "Boundary roughness in coarse-grained channels." Prog. Phys. Geog., $14(1), 42-70$. 
635 Robert, A., and Richards, K. S. (1988). "On the modelling of sand bedforms using the semivariogram." Earth Surf. Proc. Land., 13(5), 459-473.

637 Smart, G., Aberle, J., Duncan, M., and Walsh, J. (2004). "Measurement and analysis of alluvial bed roughness." J. Hydraul. Res., 42(3), 227-237.

639 Strom, K. B., Kuhns, R. D., and Lucas, H. J. (2010). "Comparison of automated image-based grain sizing to standard pebble-count methods." J. Hydraul. Eng., 136(8), 461-473.

641 Westaway, R. M., Lane, S. N., and Hicks, D. M. (2000). "The development of an automated correction procedure for digital photogrammetry for the study of wide, shallow, gravel-bed rivers." Earth Surf. Proc. Land., 25(2), 209-226.

644 Westaway, R. M., Lane, S. N., and Hicks, D. M. (2001). "Remote sensing of clear-water, shallow, gravel-bed rivers using digital photogrammetry." Photogramm. Eng. Rem. S., 67(11), 1271-1281.

647 Wolman, M. G. (1954). "A Method of Sampling Coarse River-Bed Material." Transactions, American Geophysical Union, 35(6).

649 Zhang, Z. (1998). "A Flexible New Technique for Camera Calibration." IEEE T. Pattern Anal., 22(11), 1330-1334.

651 
Table 1 Summary of the measurement specifications.

\begin{tabular}{|c|c|c|c|c|}
\hline $\begin{array}{r}\text { Measurement } \\
\text { technique }\end{array}$ & $\begin{array}{c}\text { Acoustic bed- } \\
\text { profiler }\end{array}$ & Laser-scanner & $\begin{array}{c}\text { Stereo- } \\
\text { photogrammetric } \\
\text { seasurement } \\
\text { specifications }\end{array}$ & $\begin{array}{c}\text { Improved stereo- } \\
\text { photogrammetric } \\
\text { setup (second part) }\end{array}$ \\
\hline $\begin{array}{c}\text { [Downstream } \mathbf{x} \\
\text { transverse] }\end{array}$ & $2.45 \times 2.54$ & $1.45 \times 1.45$ & $1 \times 1$ & $0.2 \times 0.2$ \\
DEM sampling & & & 1 & \\
distance (mm) & & & & \\
\hline $\begin{array}{c}\text { Theoretical } \\
\text { vertical }\end{array}$ & 0.37 & 0.05 & & \\
\hline accuracy (mm)
\end{tabular}

654

655

656

657

658

659

660

661

662 
664 Table 2 Texture coefficients extracted from bed elevation PDFs and structure functions.

\begin{tabular}{|c|c|c|c|c|c|}
\hline $\begin{array}{c}\text { Bed condition } \\
\text { Measurement } \\
\text { technique }\end{array}$ & $\begin{array}{c}\text { Screeded bed } \\
\text { profiler }\end{array}$ & $\begin{array}{c}|c| \\
\text { profiler }\end{array}$ & Laser-Scanner & Ptereo- \\
\hline $\begin{array}{c}\text { Bed } \\
\text { condition }\end{array}$ & Submerged & Submerged & Dry & Wet & Drammetry \\
\hline $\begin{array}{c}\text { Texture } \\
\text { coefficients }\end{array}$ & -0.5 & 0.81 & 0.79 & 0.86 & 0.5 \\
\hline $\begin{array}{c}\text { Skewness (-) } \\
\text { Kurtosis (-) }\end{array}$ & 4.57 & 3.8 & 4.07 & 4.26 & 3.58 \\
\hline $\boldsymbol{\sigma}_{\boldsymbol{Z}}(\mathbf{m m})$ & 1.33 & 5.76 & 5.32 & 5.32 & 5.0 \\
\hline$\Delta \boldsymbol{x}_{\mathbf{0}}(\mathbf{m m})$ & 6 & 7.2 & 9.7 & 10.1 & 6.9 \\
\hline$\Delta \boldsymbol{y}_{\mathbf{0}}(\mathbf{m m})$ & 6.8 & 8.5 & 8 & 8.1 & 9 \\
\hline
\end{tabular}

